\title{
Addressing the Exclusionary Nature of Eurocentric World History Instruction: A Systematic Literature Review
}

\author{
Yoon $\mathrm{Kim}^{1}$ and Daniel Hunter ${ }^{\#}$ \\ ${ }^{1}$ Portola High School, Irvine, CA, USA \\ \#Advisor
}

$\underline{\text { ABSTRACT }}$

The exclusion of global knowledge in favor of a condensed western-centric history curriculum casts a shadow on the fact that America is the most globalized and culturally diverse nation in the world. This paper aims to analyze the standards-based world history curriculum as taught in high school among both regular and Advanced Placement classes for its deficiency in providing a comprehensive global history. The primary topic used in the qualitative content analysis and systematic literature review is Buddhism and its spread throughout China. Especially with the curriculum change from the College Board's AP World History to AP World History: Modern, key developments in history are marginalized in favor of a direct look at history beginning in the 13th century (1200 CE onwards). Twenty-five world history instructor websites were analyzed to explore the extent of instruction on concepts related to Buddhism in East Asia. The literature review results support the hypothesis that the major world religion is sparsely covered in the greater picture of general world history. Included is a short paper covering information on the spread of Buddhism into China based on research findings from more in-depth college courses as well as simple internet browsing. This paper concludes with a recommendation that educational policies and curriculum standards address the growing diversity of the U.S. student population.

\section{Introduction}

Between 9th and 12th grade, the subject of world history is taught and offered in various courses, such as ancient history, world history, and in some measure, U.S. history. However, in many cases, world history is often lightly touched on or is an entirely optional learning course because U.S. history is required to be taught in all schools, whereas world history and ancient history are not. Since its introduction to the Advanced Placement (AP) curriculum in 2002 by CollegeBoard, the AP World History course has broken history down into nine manageable units of instruction, separated by time periods, covering a total of the last 10,000 years of human civilization.

Although ancient or world history courses cover an extended duration of time and the development of different civilizations, today's history offerings tend to focus on the Euro-centric aspects. In fact, the College Board, the organization overseeing college entrance exams and administrators of the SAT and AP exams, even modified the AP World History course, renaming and standardizing it as AP World History: Modern, the new designation for the class as of Fall 2019. The newly implemented world history course heavily focuses on European development from the 1200s to the present day, and explores the area in both breadth and depth. However, the current curriculum's sole focus on the European perspective largely prohibits the study of other cultures and civilizations in the world over the course of a year's instruction. As it is taught in the U.S., world history sees the world through the perspective of America and the events that impacted its development. 
A major example of the academic exclusion present in the AP courses is the religion of Buddhism. Buddhism, along with other globally prominent religions, is one of the oldest to be formed in human history and has spread throughout the majority of the Asian continent over the common era. Such a lack of inclusion is disturbing for a U.S. population of growing diversity when the California State Board's intent is that "Students will learn to distinguish the important from the unimportant, to recognize vital connections between the present and the past" (California State Board of Education, 1998). The wording of this standards guide, which still affects classroom learning even though it has been updated, represents an outdated view of the value of every individual culture across the globe.

\section{Focus of Inquiry}

This paper examines the general world history curriculum as taught in American high schools for units including instruction on Buddhism as it pertains to China. The author hypothesizes that since the course is taught in America according to state standards, East Asian content not directly impacting Western history is lacking. This paper aims to quantify that scarcity and present an example of what may be commonly found online and be taught in a more specific class in higher learning institutions where in-depth classes are offered. Finally, the paper makes a recommendation regarding educational standards policies that content be more in line with the student body's diverse makeup rather than its impact from a western-centric perspective.

\section{Methodology}

This study uses a qualitative content analysis as part of a systematic literature review. The systematic steps included a broad process of 1) defining, 2) scoping, 3) cataloguing, 4) coding, 5) quantifying, and 6) interpreting.

\section{Defining: Guiding Research Questions}

The research hypothesis is based on questions regarding the extent of Buddhism inclusion in the world history curriculum at a range of high schools. Questions that guided the research included "Is Buddhism specifically mentioned on a syllabus?", "Which major textbook publishers are frequently used?", "Do teachers offer supplemental information such as handouts or presentations?" "How different is the curriculum across the fifty states?" Answering these questions led to the development of categories and codes.

\section{Scoping: Limiting the Search Field}

Literature was found online using internet searches and public access to teachers' class websites. Only information from freely accessible sites was used. Websites had to be current, with a syllabus and textbook information, as well as teachers' planning notes for the year-long world history course taught. Due to this focus on education within the USA, world history courses taught outside the U.S. were not considered. Furthermore, this research was limited to public high schools, as parochial or other private schools may include supplemental information through elective classes (e.g., "World Religions") and may therefore skip the material in a world history class to teach to standards.

\section{Cataloguing: Gathering and Sorting Sources}

Initial searching revealed more hits than could be used for the purposes of this paper. From an initial group of over 100 tabs making up the top search hits on Google search, a list of over 40 teacher websites that satisfied the criteria was made. Initial review showed very little Advanced Placement, and another search yielded 3 more sites to include 
AP instructor websites. Of those sites, only 25 yielded information that did not require login credentials or access from the instructor. These 25 sites were selected to analyze for coding. Table 1 outlines and quantifies the collection process.

Table 1. Data Collection Process Overview.

\begin{tabular}{|l|l|}
\hline \multicolumn{1}{|c|}{ Google Search } & Total Results \\
\hline Preliminary results & $>100$ \\
\hline Filtering for initial criteria & 43 \\
\hline (with additional AP) & 46 \\
\hline Filtering for access & 25 \\
\hline Total analyzed & 25 \\
\hline
\end{tabular}

\section{Coding: Annotating Search Results and Categorizing}

The coding framework resulted in 14 items within 5 categories. Textbooks were not included in coding because all 25 teacher websites included the use of four major publishers (Glencoe/McGraw Hill, McDougal Littel, Holt, and Pearson). All four publishers provide textbooks for use in world history classes at the high school level and include a similar sub-section on Buddhism, which can be located by using each textbook's index. Table 2 describes the categories and their items, which are clarified in the Discussion.

Table 2. Cataloguing Criteria. The categories and items making up the coding framework.

\begin{tabular}{|l|l|}
\hline \multicolumn{1}{|c|}{ Category } & \\
\hline Mention in curriculum & Syllabus \\
\hline & Teacher's site text \\
\hline Course level & College-prep/honors (CP/H) world history \\
\hline & Advanced Placement (AP) World History/Modern \\
\hline Length of study & Text reading \\
\hline & Standalone unit \\
\hline Teacher supplement & Guided reading notes \\
\hline & Publisher outline \\
\hline & PPT/Google Slide/Slidedeck \\
\hline & Video link \\
\hline Buddhism spread & Traders \\
\hline & Monks \\
\hline & Holy texts \\
\hline & Icons \\
\hline
\end{tabular}




\section{Quantifying: Statistics from Research}

The collection group totaled twenty-five analyzed course websites $(n=25)$. The most notable trend revealed data at the extreme ends. Items were either quite high or low in percentage based on the coding framework. For example, regarding the spread of Buddhism, trade over land and oceanic routes is listed as a cause in $96 \%$ of classes $(n=24)$, whereas holy texts and icons are mentioned only $8 \%$ of the time $(n=2)$. No correlation could be seen between the 5 AP classes and the other 20 non-AP classes. $76 \%(n=19)$ of teachers offered guided reading notes to supplement the class; however, $0 \%(n=0)$ of classes offered anything like a standalone unit. Video links and slidedeck supplements were provided in all 5 AP classes and in $72 \%(n=18)$ of classes overall.

\section{Discussion}

\section{Interpreting: Narrative of Results}

The extremely high or low number of hits within the analyzed database reveal a nationwide pattern regardless of course level. The California State Standards specifically mention Buddhism four times in Grade 6 and 7 standards, yet no such mentions in high school curriculum (western-centered) in the 9-12 category despite Judeo-Christian religions mentioned throughout (California State Board of Education, 1998). Though this standard has been updated since 1998, the world history courses as currently taught clearly do not address Buddhism in any complete form. Textbooks from the major publishers include the basic knowledge of Buddhism's spread into China in parallel with trade along the Silk Road and the Indian Ocean sea routes. However, with the transition into the AP World History: Modern course offering in 2019, students have even less opportunity to learn about ancient and pre-modern history, since the course begins with the period of 1200 C.E. onwards. In comparison to commonly searchable information about the spread of Buddhism into China and college curriculum offerings, the world history courses as taught in American public schools barely scratch the surface of the religion's rich history, much of which takes place within a thousand years before AP World History: Modern even begins.

\section{Breadth and Depth in College Offerings and Outside Sources}

While the data highlight the truth that the HS curriculum offers little opportunity to explore non-standard knowledge in depth, a simple Google search, as well as a more-involved database search, reveals much more specific information than can be found in the most commonly used history texts in high school. A multitude of primary, secondary, and narrative sources explain the spread of Buddhism into China for audiences from casual to scholarly interest. Compared to the information publicly accessible through school-provided access to databases and sites such as Google Scholar, the high school standards provide little knowledge for students to gain a foundation or interest in exploring topics like Chinese Buddhism.

In contrast, in university classes, full-semester length courses are offered that provide greater insight into East Asian culture and identity for students to begin exploring scholarly topics. For example, a current course offered at NYU: Shanghai, The Concept of China, provides options to discuss the influence of Buddhism as it spread during the Han and reached its height during the Tang dynasty as it explores Chinese national and cultural identity (Coursicle, 2021). Similarly, Introduction to Buddhism at UCLA investigates Buddhism and the "religious doctrines and meditative practices most essential to various Asian traditions" (UCLA CCLE, 2021). Moreover, websites pertaining to the tourism industry of Buddhist heritage sites also offer a richer history and background of Buddhism for travelers to appreciate its rich history and connection to Chinese culture today. 


\section{The Spread of Buddhism into China Beyond High School Course Content}

The following is a short synthesis paper covering information learned outside of the scope of a U.S.-taught world history course. It is included to provide an example of how much information can be left ignored when standards determine what is "important" for students to learn.

\section{Roots and Early Causes of Popularity}

Buddhism has been rooted since the early centuries, originally cultivating in India and spreading to China via the Silk Road trades during the time of the Han dynasty (206 B.C. - 220 A.D.) governance, according to research done by the Asia Society (Foy). The religion mainly reached China as Indian Buddhist monks traveled to East Asia through the Silk Road. As shown in the previously presented research, many believe that the significance of Buddhist development within China lies mostly in the Silk Road trade routes, but it is rather the Chinese's own way of adapting to Buddhism that makes the religion one of the most relevant in today's world. The spread of Buddhism throughout the vast nation of China also holds much importance in the fact that there was little to no bloodshed during the process of cultivation. Unlike other major religions such as Catholicism and Islam, which suffered multiple bloody events throughout their history, such as the Battle of Uhud (625) and the Catholic Crusades (1095-1271), Buddhism lacks notable uproars of violence during its centuries of popularization. The most significant reasoning behind the peaceful process of expansion that Buddhism went through was that the Chinese people had altered Buddhist beliefs to better suit their own culture and society, ultimately gaining the support of the poor, the rich, and even the royalty.

Before Buddhism became a prominent religion in China, the country and its people mainly followed the ideals of Confucianism, which is a religion that focuses heavily on social ethics and philosophy. It was treated as more of a household belief for most Chinese individuals rather than a spiritual source of guidance. Thus, Confucianism lacked a unified state of religion, allowing Buddhism to ease its way into the Chinese society. Although Buddhism focused mainly on spiritual devotion and peace within one's mind, which are all heavily opposed to the societally ethical Confucian beliefs, the Chinese people were easily attracted to Buddhism due to the fact that the religion offered assurance of prosperity in the spiritual aspect of life. Such a viewpoint on religion rarely crossed Chinese society before the spread of Buddhism. Believing in the low-cost spiritual guidance, a portion of the low-income Chinese had begun to support Buddhism, becoming monks to devote their lives to finding inner peace. Furthermore, Buddhism even offered direct financial benefits, as monks often had their taxes cut by the government since they were considered to work under religious institutions. It is concluded by researchers that many of China's working and poor class of citizens were attracted to the monastic life of Buddhism soley for utilitarian purposes such as tax exemptions (Lewis et al., 2021). Though attempts of nullifying the tax cuts were made, the reduced amount of required fees was a key attraction of Buddhism during most years of its popularization, causing many more of the poor within China to follow the religion. One reason that the poor, which was, like many other countries, the largest body of population within China, showed dramatic support for Buddhism during its cultivation was the financial benefit that was offered.

Although it was supported by the poor, Buddhism was still a new, foreign religion being adopted into Chinasuch new ideas often failed to be accepted without the rich and royalty's support, as they held most of the economic power within the nation. Buddhism, however, earned the support of the economically and politically powerful body of China's population by being able to relate to China's pre-existing ideals. It is true that Buddhism benefited the poor because it was largely opposed to the societally stubborn Confucianism (Teiser and Velleren, 2011), but in fact, the religion also aligned with some important Chinese ideals mainly used by the royalty. The cakravartin ideal of Buddhism, which states that a universal monarch ruled the world with benevolence, was popular among Chinese elites (Zurcher, 2013). This was because the cakravartin ideal had a similar concept to the Mandate of Heaven, which was the policy that gave the Chinese emperor undoubted power. The Chinese elites were able to utilize such benefitting Buddhist ideals to keep easier control of the nation, and also strengthen the authority of the government. 


\section{Assimilation by Chinese Culture and Government}

As much as Buddhism had its differences with traditional chinese beliefs such as Confucianism and Daoism (Taoism), the religion was assimilated by the Chinese society to mix in with such pre-existing ideals, thus increasing Buddhist impact. Many Chinese citizens during the period of Buddhist assimilation prayed to gods of other religions such as Taoism, along with Buddha, but still considered themselves as Buddhists (Pang, 2021). While its popularization continued, Buddhism progressively became a household set of values for most Chinese families and individuals much like Confucianism, while also maintaining its spiritual demands. As the aforementioned information suggests, the cause of Buddhist assimilation was that it had benefitting ideals that aligned with traditional Chinese culture. Soon enough, Buddhism also became part of the traditional Chinese culture because of its flexibility. By this point of its popularization, Buddhism seemed much closer to be Chinese beliefs rather than Indian.

Similar to many other religions, Buddhism also had buildings for believers to gather and become involved in religious activities. Such buildings were called monasteries, and they were costly structures to build during the period of Buddhist popularization. The Tang dynasty, which was the time period of the most rapid spread of Buddhism, was the originating source of most ancient Chinese monasteries. The laity, or the common people without expert knowledge in religion paid for the majority of the monastery constructions, as they were persuaded that committing such deeds would certainly lead them to a better future in the next life. They often contributed in ways such as donating their property or talent to solely work for the funding of Buddhist monasteries (Yang, 1950). The desire to gain earthly rewards, which was a mentioned point in the earlier paragraphs, heavily outweighed the consideration of real-time earnings after donating valuable aspects of life such as entire regions of land. The benefits for the Buddhist religion were significant- more people gave up on their property and possessions in order to become monks, deciding to reside in monasteries while living a realistically undesiring lifestyle mainly for causes related to otherworldly benefits or exemption from heavy federal taxation $(\mathrm{He}, 2011)$.

The governing state of China, however, was not consistently supportive of Buddhist constructions throughout the nation. Although it was true that the royalty and wealthy were intrigued by Buddhism's alignment with Chinese governmental ideals, the Tang were mainly Daoists, despite the fact that Buddhism's golden age was the Tang Dynasty. Though the Tang later favored Buddhism over any other religion, they initially believed that the Chinese economy would have been disrupted by the amount of taxing being avoided by the increasing number of monks and nuns. Therefore, many Buddhist religious workers were forced to return to common taxpayers. It is reported by researchers that around 845, over 260,000 monks and nuns all across China returned to common life (Onion, 2017). Moreover, construction of temples and monasteries were widely halted during the period of Tang Emperor Wuzong's rule, as 4,600 Buddhist monasteries and 40,000 temples were shut down in his reign (Palumbo, 2017). Even after all the attempted containment of Buddhism that the Tang Dynasty made, the religion continued to engulf China throughout the period, and the following government of the Song Dynasty immediately continued to work on Buddhist popularization.

\section{Result of Assimilation and Impacts Today}

Past the Tang dynasty, Buddhism was safely established and practiced as one of China's most popular religions along with Daoism. Buddhist influences were often shown in artistic ways, as many statues were constructed and paintings were drawn, mainly revolving around the Buddha. However, most Buddhist art since the Song dynasty varied drastically from traditional Indian Mahayana Buddhist artworks. A significant example of such a difference is the Laughing Buddha, which is a folktale later turned into a famous statue during the Song dynasty. The Laughing Buddha, or Budai, is a tale in which the Buddha is pictured as a fat, smiling man who was beloved by the children and poor, to whom he would give rice and sweets from a sack that he carried around (Roos, 2018). Though this tale has slight similarities to Buddhist ideals such as selflessness, the visualization of the Buddha, who is the main figure of the religion, largely differs from that of the root Buddhism formed in India. The Budai statue is widely popular throughout China today, and has been one of the most iconic Chinese Buddhist folktales since its emergence around 907-923 CE 
(O'Brien, 2019). This drastically different representation of the Buddha demonstrates a distinctive cultural take on Buddhism by the Chinese. Moreover, development of the woodblock printing technology during the Song dynasty rapidly enhanced the spread of literature and knowledge. Sinicization of Buddhist ideals and teachings were quickly processed during the Song dynasty, along with Confucian reinvigoration as it fused with Buddhism to retain Chinese popularity.

Moving forward by multiple centuries, the assumption of governmental power by the Chinese Communist Party (CCP) in 1949 began religious suppression throughout all of China. Research states that the CCP offered religious freedom to the Chinese citizens, but believed that religion in itself was a nuisance to the revolutionary ideals, and therefore promoted non-violent campaigns against any religious activities (Yu, 1971). The CCP still remains in control of the Chinese government today, and recognizes Buddhism as one of the five religions it formally allows within the nation, although the party has refused to publicize any specific statistics regarding religion within China, thus making data collection extremely difficult (Albert, Maizland 2020). However, surveys of religion in China conducted by researchers have "offered an estimate of about 245 million Buddhists, significantly higher than the official figure of 100 million traditionally given by the government and the Buddhist Association of China" (Buddhistdoor 18). In general, a significant number of Chinese citizens, despite the anti-religion campaigns of the CCP believe that Buddhism is incorporated within their culture, as a large group of people within the nation also follow other traditional Chinese beliefs that are originated from or fused with Buddhist ideals.

In conclusion, Buddhism's introduction to the Chinese civilization during the Han dynasty gained the interest of both the rich and poor civil classes, leading to rapid incorporations to the country, and eventually the assimilation by the Chinese culture. The key factors of Buddhism that largely contributed to its popularity such as the financial benefits offered, the ability to fuse with other pre-established Chinese beliefs or ideals, the construction of monasteries and temples, and finally the spreading of Chinese Buddhist tales and art through methods such as woodblock printing or statues have all impacted today's practice of Buddhism within China. Its varied ideals from the original Mahayana Buddhism stands as not just an interpretation of the religion by the Chinese, but rather as a deeply rooted belief that was developed over centuries with growing popularity.

\section{Conclusion}

This study provides a concrete example of the exclusion of historical content when classes are standardized to the Eurocentric perspective. World history classes around the globe offer varying curricula based on government and local standards. In the United States, these standards are developed at the state level. However, as seen in this sample of classes taught throughout America, a concept less impactful to the development of America, such as Buddhism (compared to Judaism and Islam), may be deemed less "important" than other topics widely covered throughout the K-12 education. By high school, students must be able to develop more critical thinking skills and take on more academically difficult_ and specific_-information. While classes may provide opportunities through independent research, the burden is on students to find topics of interest.

Educators and policy makers could benefit the growing diversity of the U.S. student population. In fact, changes to curriculum are currently being made as educators address topics such as the presence of indigenous peoples in America before European colonization and the civil rights movement beyond the 1960s. The fact that Buddhism is not presented as commonly as a subject like the Great Depression should not necessarily suggest that it is insignificant, just out of the scope of the world history curriculum as given by state standards. However, the lack of inclusion of a topic that could raise greater curiosity and interest in world history must be addressed. Educators should consider the benefits of a more comprehensive world history curriculum that continues throughout the years of high school as opposed to giving each academic subject its own year of limited instruction. World History could be more inclusive even if US history remains based on impact on America. 


\section{Limitations}

Educators around the globe must wrestle with their own policies and limitations in constructing a meaningful curriculum. However, this study limited its scope to US high schools. Furthermore, the information presented for research was limited to freely accessible syllabuses on public school websites. It is possible (and likely) that information within inaccessible course materials, such as lectures, PowerPoint outlines, and video lessons could contain specific information that could only be found with login credentials or teacher inquiry. Thus, this study cannot be considered unbiased without teacher interviews and further clarifications regarding Buddhism taught during classroom instruction. In retrospect, not all categories were required to address the hypothesis, and some categories could have been included. Given more time and access, a different approach of email questionnaires to history teachers, with interviews for clarification as needed, might have sufficed.

\section{Acknowledgements}

I would like to thank Mr. Daniel Hunter for his instruction in history this year and for approving my independent research as a mentor.

\section{References}

Albert, E., \& Maizland, L. (2020, September 25). The State of Religion in China. Council on Foreign Relations. https://www.cfr.org/backgrounder/religion-china

Buddhistdoor. (2018, January 22). Buddhism in China Today: An Adaptable Present, a Hopeful Future.

Buddhistdoor. https://www.buddhistdoor.net/features/buddhism-in-china-today-an-adaptable-present-a-hopefulfuture

California State Board of Education. (1998). History-Social Science Content Standards for California Public Schools: Kindergarten Through Grade Twelve. https://www.cde.ca.gov/be/st/ss/documents/histsocscistnd.pdf

Coursicle. (2021). GCHNSHU 110 - The Concept of China. In Coursicle app. Coursicle.

Foy, G. (n.d.). Buddhism in China. Asia Society. https://asiasociety.org/buddhism-

china\#: : text=Buddhists\%20gained $\% 20 \mathrm{a} \% 20$ lexicon $\% 20$ that,in\%20popularity $\% 20$ and $\% 20$ political $\% 20$ influence

He, Y. (2011, September). Buddhism In The Economic History of China. McSphere: McMaster University Libraries Institutional Respository. https://macsphere.mcmaster.ca/bitstream/11375/11433/1/fulltext.pdf

Lewis, J. Wilson, Hsu, Cho-yun, Suzuki, Chusei, Wilbur, C. Martin, Dull, Jack L., Lieberthal, Kenneth G., McKnight, Brian E., Elman, Benjamin, Young, Ernest P., Chen, Cheng-Siang, Twitchett, Denis C., Franke, Herbert, Silbergeld, Jerome, Keightley, David N., Zürcher, Erik, Rawski, Evelyn S., Chan, Hoklam, Liu, James T. C., Hucker, Charles O., Feuerwerker, Albert, White, Lynn and DeWoskin, Kenneth J. (2021, May 25). China. Encyclopedia Britannica. https://www.britannica.com/place/China

O'Brien, B. (2019, January 28). Who Is the Laughing Buddha? A Surprising Piece of Buddhist History. Learn Religions. https://www.learnreligions.com/the-laughing-buddha-

449784\#: :text=The\%20Laughing\%20Buddha\%20emerged\%20from,now\%20the\%20province\%20of\%20Zhejiang 
Onion, A., Sullivan, M., \& Mullen, M. (2017, December 21). Tang Dynasty. History.com. https://www.history.com/topics/ancient-china/tang-dynasty.

Palumbo, A. (2017). Exemption Not Granted: The Confrontation between Buddhism and the Chinese State in Late Antiquity and the >First Great Divergence< Between China and Western Eurasia. Medieval Worlds, medieval worlds (Volume 6. 2017), 118-155. https://doi.org/10.1553/medievalworlds_no6_2017s118

Pang, K. (2021, March 18). Buddhism in China - Ancient History to Beliefs Today. https://www.chinahighlights.com/travelguide/buddhism.htm

Roos, D. (2018, August 24). That Fat, Jolly Fella Isn't Buddha. HowStuffWorks. https://people.howstuffworks.com/that-fat-jolly-fella-isntbuddha.htm\#: :text=According $\% 20$ to $\% 20$ accounts $\% 20$ written $\% 20$ centuries,and $\% 20$ sweets $\% 20$ from $\% 20$ his $\% 20$ sac $\mathrm{k}$

Teiser, S., \& Verellen, F. (2011). Buddhism, Daoism, and Chinese Religion. Cahiers D'Extrême-Asie, 20 , 1-12. Retrieved May 26, 2021, from http://www.jstor.org/stable/44171506

UCLA Common Collaboration Learning Environment. (2021). Introduction to Buddhism. In UCLA CCLE Shared System. UC Regents.

Yang, L.-sheng. (1950). Buddhist Monasteries and Four Money-raising Institutions in Chinese History. Harvard Journal of Asiatic Studies, 13(1/2), 174-191. https://doi.org/10.2307/2718163

Yu, D. (1971). Buddhism in Communist China: Demise or Co-Existence? Journal of the American Academy of Religion, 39(1), 48-61. Retrieved May 28, 2021, from http://www.jstor.org/stable/1461680

Zürcher, E. (28 Nov. 2013). Buddhism in China. Leiden, The Netherlands: Brill. doi: https://doi.org/10.1163/9789004263291 